\title{
Natural oriffice transluminal endoscoping surgery - transgastric approach
}

\author{
Smid D, Molacek J, Vesely V, Treska V \\ Surgical Clinic, University Hospital in Pilsen, Czech Republic. davidsmid@atlas.cz
}

\begin{abstract}
Background: Natural Oriffice Transluminal Endoscopic Surgery (NOTES) is a newly developed miniinvasive surgical method for ensuring an approach into the abdominal cavity through the wall of the organ being accessible to the endoscopic examination. We can use the transcolonic, as the case may be, transrectal, transvaginal or transgastric approach

Methods: We performed the experiment in thirty pigs which were divided into two groups. In the first group, we performed pure NOTES exploration of the abdominal cavity with the transgastric approach, the formed defect of the stomach was closed by the OTSC clip. In the other controlled group, a classic laparoscopic exploration of the abdominal cavity was performed. Ultrasonography of the abdominal cavity, assessment of inflammatory parameters and clinical monitoring of the animals clinically were performed regularly postoperatively. After two weeks, the animals were put to death and an autopsy was done. The results of both groups were mutually compared, focusing on safety of the gastrotomy closure and the occurence of infectious complications.

Results: No serious postoperative infectious complications were observed in both groups, the closure of the defect of the stomach wall was always sufficient. The other monitored results were comparable.

Conclusion: Using the OTSC clip is a safe choice of the gastrotomy closure. It is supposed to be used in limited cases, also if perforation of the digestive tube is being solved. Nowadays, using the NOTES technique as a surgical method in the abdominal cavity is not suitable (Tab. 2, Fig. 3, Ref. 27). Full Text in PDF www.elis.sk. Key words: NOTES, OTSC clip, gastrotomy closure, experimental study.
\end{abstract}

NOTES - Natural Oriffice Transluminal Endoscopic Surgery is a newly developed miniinvasive surgical method when an approach to the abdominal cavity is ensured through the wall of the organ being accessible to the endoscopic examination. Transvaginal, transgastric, transcolonic and as the case may be also transrectal approach may be used and in the literature transvesic approach is mentioned, which has considerable limits with regard to the urethra size $(1,2,3)$. This is a very new and surely controversial surgical technique one does not have much experience with, that's why its use is minimal in human medicine and so far it has been used more in experimental surgery. In spite of that fact, there are already some literature data of its use in human medicine $(2-8)$. The next very essential fact is a present level of the technical maturity of instrumentarium representing strong limits of this method these days. With regard to the mentioned facts, in the case of its use in human medicine, often a laparoscopic approach for the classic camera is used due to a better orientation in the abdominal cavity $(8,9)$. That's why it is also necessary to differentiate between the so called pure NOTES technique, when only the NOTES technique is used, and so called hybrid NOTES technique, which uses laparoscope assistance. Our department has been using procedures

Surgical Clinic, University Hospital in Pilsen Czech Republic

Address for correspondence: D. Smid, MD, Zluticka 5, CZ-323 00 Plzen, Czech Republic.

Phone: +420.604897325

Acknowledgement: This animal experiment has been supported by Ministry of Health grant number IGA NS10241-3. reminding of the NOTES technique for a longer time. It is a transanal endoscopic method of rectum surgery (TEM tumor excision) and transgastric nature of pseudocystogastroanastomosis which is used in the treatment of symptomatic cysts of the pancreas. Both methods have their limits and every diagnosis is not suitable for these surgeries. The aim of our work was to obtain first experience with the NOTES technique in an experimental animal model and to prove a possibility of using the transgastric approach to the abdominal cavity and to ensure its safe closure.

\section{Methods}

In our department, an experimental study was perforemd in an animal model in progress with the aim to prove possibilities of the pure NOTES technique with transgastric approach in practice, to compare its benefits and risks with common laparoscopy and to evaluate its difficulties and possibilities of realization with the present instrumentarium being available. The experimental study was authorized by the Ethics Committee of Faculty of Medicine of Charles University in Pilsen for work with laboratory animals. We especially focused on the safe closure of incision in the stomach wall (gastrotomy) and the formation of postoperative intraabdominal complications. No other surgeries of the abdominal cavity were performed. After finishing this surgery, a two-channel flexible endoscope connected to the optical system with a recorder (Olympus EXERA II) was used, further, the classic endoscopical instrumentarium (needle knife, pliers) was also used. To close the 
gastrotomy, a special OTSC clip (over the scope clip - made by OVESCO) was applied. The surgery was equally performed by two doctors with an endoscopic nurse.

A pig was used for this experiment. All animal performances were hold pursuant to Decree for Work with Experimental Animals ( 111 Decree No. 207/2004 Code of Law). The body weight of the animals was about 25 kilograms at the beginning of this experiment. Altogether 30 female animals being equally divided into two groups were used. The animals were operated in an experimental operating room. They were generally anaesthetized (premedication: Atropin 0,5 mg (Atropin biotica, BB Pharma, Czech Republic) + Azaperon 60 mg i.m. (Stresnil, Janssen Pharmaceutic, Belgium), the introduction into general anaesthesia: Ketamin $2 \mathrm{mg} / \mathrm{kg}$ t.hm. (Calypsol, Chemical Works of Gedeon Richter, Hungary), keeping in general anaesthesia: Propofol $1 \% 2 \mathrm{mg} / \mathrm{kg} \mathrm{t} . \mathrm{hm}$. (Propofol $1 \%$, Fresenius Kabi, Austria) + Atracurium $0.3 \mathrm{mg} / \mathrm{kg}$ t.hm. (Tracrium, GlaxoSmithKline, Italy), Fentanyl $2 \mathrm{ug} / \mathrm{kg}$ t.hm./min (Fentanyl Torrex, Torrex Chiesi Pharma, Austria), orotracheal intubation and connection to the artificial pulmonary ventilation (Siemens-Elema) - Volume Control Ventilation, FiO2 0,4 PEEP 0.2 kPa, MV 14/min, $\mathrm{Vt} 8 \mathrm{ml} / \mathrm{kg}$ t.hm. After the introduction into general anaesthesia, all animals of Group A(15 animals) were monitored before the surgery. A sample of the hypofaryngus for microbiological screening was taken and also a blood sample for laboratory screening (leukocyte level and CRP-value) from a peripheral vein of the auricle. While the animals were lying on their back, we performed classic esofagogastroscopy (Olympus GIF-2T 160) and evaluated the endoscopic diagnosis. After that a short gastrotomy of about two centimetres on the front stomach wall was performed with the needle knife and an approach with the endoscope into the empty abdominal cavity was obtained. Pneumoperitoneum was formed so that the abdominal wall could be distanced from the bowels and a handling area in the abdominal cavity could be formed. The abdominal cavity (liver, gallbladder and intestines in the limited range) was optically reviewed. A sample of fluid of the abdominal cavity was taken for microbiological screening with a long catheter by aspiration. Further, the pneumoperitoneum was sucked and the endoscope removed from the abdominal cavity. The instrumentarium was fixed for using the OTSC clip (over the scope clip) to the endoscope and put into the stomach. By placing the over clip on the stomach wall into the incision place with grip pliers the gastrotomy was closed and the surgery was finished. We postoperatively ensured sufficient analgesia and monitored the animals. After the surgery, the animals were practically able to ingest in an oral way. It was only fluid on the surgical day, then normal food starting the following day (granules, grout). In the postoperative time, overal thriving of the animals (weight gain) and their behaviour were evaluated. The animals were examined on the third, seventh, tenth and fourteenth postoperative days. We always performed transabdominal sonography, weighed the animals and took a blood sample from the femoral vein at the same time when we monitored the values of CRP and the number of their leukocytes. On the fourteenth postoperative day, the animals were sarificedthrough deep general anaesthesia by administering cardioplegic solution ( $60 \mathrm{ml} 7.45 \% \mathrm{KCl}$ i.v.) and an autopsy was performed. We focused on the presence of an intraabdominal or intrathoracic complications, tightness of the gastrotomy closure, state of the stomach wall and the clip presence. This postopeative monitoring was indentical for both checked groups of animals-suitable photo supplement.

Group B was a control one (there were 15 animals), after the introduction into general anaesthesia being made in the same way as in the case of Group A, we took a sample of the hypofaryngus for microbiological screening and a blood sample for laboratory screening. After preparing the operation area, we formed capnoperitoneum for all the animals in the position of lying on the back with the Verres neddle and put a laparoscopic disposable port of 15 milimetres supraumbilically in the middle line. By using the flexible endoscope (Olympus GIF-2T 160), exploration of the abdominal cavity was done. We optically reviewed livers, gallbladder, stomach and accessible intestines and took a fluid smear of the abdominal cavity for microbiological screening. The incision in the abdominal wall after the port was closed by using a vicryl stitch and the wound was closed with stitches. The animals were monitored postoperatively in the same way as in the case of Group A, after fourteen days we put them to death in deep general anaesthesia in the same way as in Group A and performed an autopsy. We focused on the presence of an intraabdominal or intrathoracic complication, early infection, wound dehiscention or other complications. The obtained results of both groups were mutually compared by us.

\section{Results}

No intraoperative or postoperative death of animals were observed, no alteration of the animal behaviour in the postoperative time was found. In one case of Group A, a peroperative complication was observed, which was a small perforation of distal esophagus while the endoscope was being inserted with the set OTSC clip. In spite of that fact, we managed to get an approach to the stomach and closed the gastrotomy. The perforation of the esophagus was not treated and monitoring of the animal in Group A continued. During regular ultrasound controls of animals on the mentioned postoperative days, normal ultrasound diagnosis in both groups was always established, it means there were no intraabdominal complications. A bigger amount of effusion in the abdominal cavity was noticed only in one case of Group B. In the control group (Group B), cutaneous dehiscentation was observed, the presence of early infection in five cases, the closure of the abdominal cavity was always sufficient. During the autopsy, no intraabdominal or intratheracic complication were found. In Group B, we found a bigger amount of serious effusion in the abdominal cavity only in one animal during the autopsy. It was the same animal in that effusion was found even during the ultrasonographic examination. Further, a short stenosis of $50 \%$ of the distal esophagus was found in one animal of Group A having no clinical response, the animal thrived in a normal way like the other ones. The stenosis was caused by the healed perforation of the distal esophagus noticed during the surgery itself. Performing an autopsy, we evaluated the presence of the OTSC clip on the stomach wall in the animals of Group A which was found in the original position in 11 animals. We did not find the clip in the other ones. The released clip was not found even 


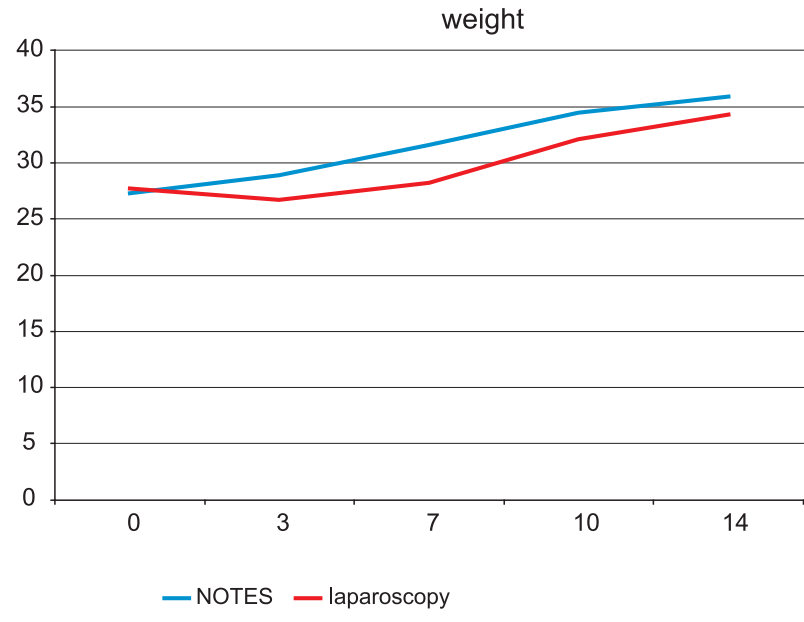

Fig. 1. Average animal weights.

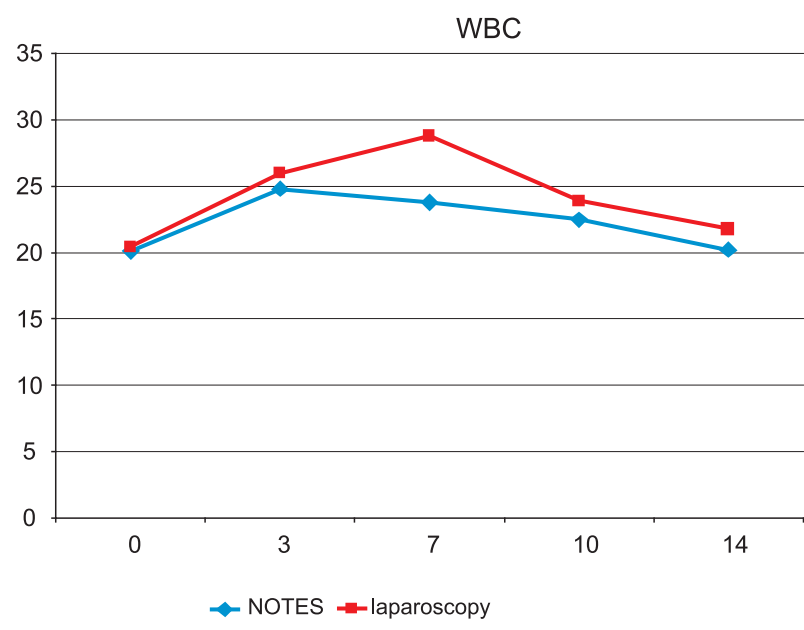

Fig. 2. Level of white blood cells.

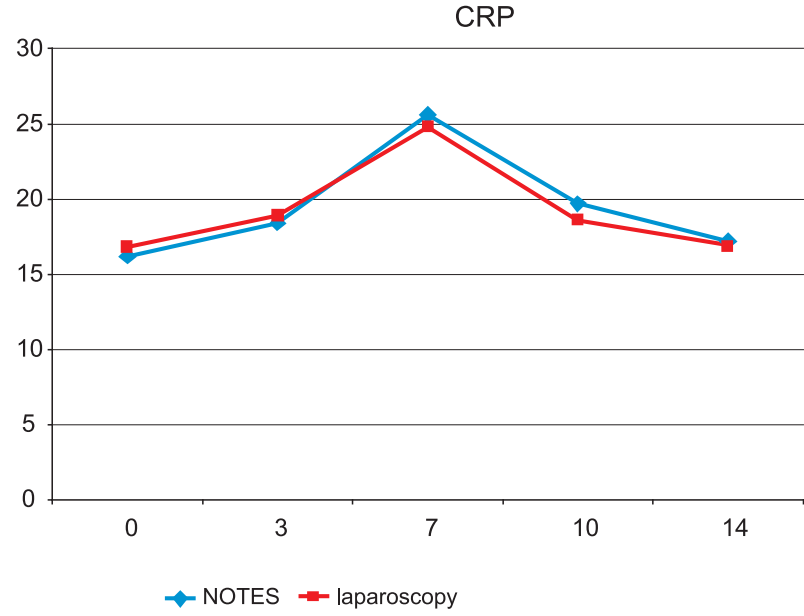

Fig. 3. Level of C-reactive protein.

in other parts of the digestive system, it is supposed to have gone out per via naturales because there were no symptoms of intestinal obstruction. After removing the clips, the stomach wall was always vital without any symptoms of defective blood supply in the other animals. In the place of the original gastrotomy, there was always a fixed sharply demarcated scar. The surrounding gastric mucosa was of a macroscopicly normal appearance. As mentioned, we found cutaneous dehiscention without damaging the strength of the abdominal wall in 5 animals in the control group. In Group B, we found early infection in 14 animals, there was no other complication. The microbiological diagnosis of animals' hypofaryngus was almost the same in both groups of animals, it was always a microbial flora containing rotting bacteria. In Group A, a bacterial contamination of the abdominal cavity was detected in all animals caused by microbial agens from the hypofaryngus. However, it was always without clinical response and there no antibiotic prophylaxis or therapy were used. As for Group B, the abdominal cavity was steril, only in a few cases, there was found a bacterial contamination, but this contamination was probably caused by taking a sample or the following manipulation with the sample because we could see no majority consensus with the microbial flora of hypofaryngus and there was a low titre of bacteria. Overall thriving of animals was evaluated by their weight gain. Both groups of animals obtained the same portion of diet having the same ingredients. In Group B (control group), we found a moderate weight loss during the first measurement, it means on the third postoperative day, after that the animals started gaining weight. But in spite of thet fact the weight gain was lower in comparison with Group A (Fig. 1).

On the day of putting the animals to death, the average body weight in the animals of Group A was higher than in Group B (A $=35.9 \mathrm{~kg}, \mathrm{~B}=34.3 \mathrm{~kg}$ ). The worse thriving of animals after laparoscopy can be caused by a bigger operative stress which can give rise to bigger postoperative pains and overall deprivation of the organism. We determined the value of $\mathrm{C}$ - reactive protein (Fig. 3 ) and the number of leukocytes (Fig. 2).

The duration of the performed surgeries was measured, the times are summarized in Table 1. First, the duration of the NOTES technique was significantly longer, however, the duration became shorter depending on the growing number of surgeries. The durations of both surgeries were nearly the same at the end of this experiment. The NOTES surgery is a bit longer. The summary results are in Table 2 .

Tab. 1. Duration of the performed surgeries.

\begin{tabular}{ccc}
\hline Animal number & NOTES & Laparoscopy \\
\hline 1 & 48 & 38 \\
2 & 51 & 31 \\
3 & 46 & 26 \\
4 & 43 & 33 \\
5 & 51 & 34 \\
6 & 40 & 28 \\
7 & 45 & 29 \\
8 & 48 & 31 \\
9 & 32 & 30 \\
10 & 48 & 27 \\
11 & 39 & 34 \\
12 & 41 & 29 \\
13 & 36 & 34 \\
14 & 37 & 29 \\
15 & 42 & 33 \\
\hline average(min) & 43 & 31 \\
\hline
\end{tabular}


Tab. 2. Summary results.

\begin{tabular}{lcc}
\hline Group & A & B \\
\hline Type of surgery & Notes & Laparoscopy \\
Number & 15 & 15 \\
Average weight before surgery $(\mathrm{kg})$ & 27,3 & 27,7 \\
Final average weight $(\mathrm{kg})$ & 35,9 & 34,3 \\
Average surgery time (min) & 43 & 31 \\
Intraoperative deaths & 0 & 0 \\
Intraoperative complications & 1 x oesophagus & 0 \\
& perforation & \\
Postoperative deaths & 0 & 0 \\
Postoperative complications & 0 & $5 x$ skin dehiscence \\
Wound infections & - & 14 \\
Ultrasound examination & Normal state & Normal state \\
Thoracic complications & 0 & 0 \\
Abdominal complications & 1x distal oeso- & 0 \\
& phagus stenosis & \\
Number of finds clip & 11 & - \\
\hline
\end{tabular}

\section{Discussion}

The NOTES technique has been ,an up-to-date“ topic of special discussions, especially among internists - gastroenterologists for a few years because the NOTES technique is a certain shift of boundaries of their therapeutic options. Another branch being interested in the NOTES technique is modelling, where a major accent is put on external appearance and any scar, however small it may be, means a serious cosmetic problem. In this case, the cosmetic effect is an obvious advantage of the NOTES technique. But the question arises whether the cosmetic contribution of the NOTES technique exceeds its other risks and disadvantages.

Besides, one of the main ideas which was taken into consideration at the launch of the NOTES technique into the market was a possibility of the reduction of financial treatment costs. The NOTES technique was developed in the U.S.A. where the hospitalization means a big participation in the price of surgery. That's why an idea arised to "operate" patients in their home environment, thereby the treatment costs would be radically reduced. The team would come to the patient's home, performed a surgery and the following monitoring would be in charge of by one nurse staying with the instrument equipment in the patient's house. So overall treatment costs would be reduced. However, it is not a medical question suitable for a discussion now $(1,10)$.

The topic being suitable for this discussion is a question who should perform surgeries - surgeons, gastroenterologists, a common team? Internists endoscopists have much experience with endoscopic methods of the digestive system, diagnostic ones, of course, some of them have experience with therapeutic ones. Apart from the ERCP technique, there are mostly endoscopic polypectomies, mucosectomies, taking biopsy samples and putting stents in a limited number. But these are always endoluminal surgeries not being related to the empty abdominal cavity and other organs. If the surgery is performed without any complications, there is no need for the surgeon's co-operation. The very opposite is an occurence of complications, e.g. perforation of the digestive tube, hemorrhage (incidence of perforation is mentioned 0 .to be $033 \%$ in esofagogastroduodenoscopy, in the range of 0.05 to $0.2 \%$ in di- agnostic colonoscopy, literary sources state the occurence of perforation in therapeutic intestinal surgeries in the range of $0.5-3$ $\%)(11-15)$. The surgeon is called in most cases and the patients is entrusted with him. Nowadays, the alternative solution of perforation of the digestive system is to use the over clip and antibiotic therapy in certain conditions, which is not, however, generally widespread $(11,12,16-21)$. The question is still who should solve an acutely occured complication during the NOTES surgery - the surgeon, gastroenterologist? The next question is an available place for performing the surgery - the gastroenterologic department or operating theatre? The topic to be discussed is also a safety of the surgery. At first, it is necessary to go safely through the wall of the organ and ensure approach to the abdominal cavity. After finishing the gastrotomy, we can use e.g. the needle knife. In our experiment, there was no complication related to the gastrotomy. The same way could be admitted on other places of the digestive systemand we can consider this safe. Another question is how to avoid the contamination of the abdominal cavity by the microflora from places of the endoscope way (oral cavity, stomach, intestine, vagina). We reduced the risk of bacterial contamination by antiseptic washes of the appropriate organ against the penetration into the abdominal cavity to some extent (22). The possible solution is to use the over tube which is put on the endoscope and fixed with the end in the organ wall after going into the abdominal cavity, in our case, it is the wall of the stomach. The proximal end is outside the patients, among the teeth in the oral cavity in our case. So we can ensure a continuous and "clean" way from the outside environment (from the oral cavity) into the abdominal cavity. There are various kinds of over tube, some of them are only "an approach way", the other ones are lockable in the set position and mean a possible fixation of the set working position for the endoscope. Using these adjustable over tubes improves the manipulation in the abdominal cavity, it is not necessary to look for an initial working position in an arduous way back after pulling out the endoscope from the abdominal cavity and its return every time. This claim was practically proved by us, thanks to the international help, we had a possibility to try a borrowed adjustable prototype of the over tube. It is a big problem how to ensure air pressure stability in the abdominal cavity. The classic endoscopic insuflators enable no controlled pressurization on the setpoint like the laparoscopic insuflator that's why there is a risk of excess pressure in the abdominal cavity and following complications $(23,24)$. During the manipulation with the endoscope in and out, we can see pressure drop along the endoscope and the uncontrolled rapid pressure loss which causes sudden worsening of clarity of the operating place during the abdominal wall drop. In the case that this happens in the electrocoagulation work, the intraabdominal organs can be injured. A partial solution is to use the over tube having sealing flaps (like the laparoscopic port) at both endings and avoid pressure drop. However, it is no solution for a possible excess pressure. We had also a possibility to try this over tube, too. If it is used, there is no risk of pressure drop in the abdominal cavity but the endoscope manipulation gets worse at the same time and the pressure grows in the abdominal cavity that's why it is necessary to let out the pressure again. The next question is a safe closure of the formed hole in the organ wall where we got approach into the 
abdominal cavity. We checked that using the OTSC clip meant a safe way of the stomach closure, the assumption is a possible use in the whole digestive system. Using the over clip brings some risks and disadvantages, too. The main disadvantage is only one possible putting-on because the over clip cannot be removed in an endoscopic way after its putting-on. In our case, we always managed to put the over clip to the intended position for the first time, the applicator of the over clip slipped out of the end of the endoscope in one case. We had to pull out the end with the clip by the extraction forceps and to repeat putting and the experiment of the gastrotomy closure, which was successfully done. Further, we do not know how the tissue will react under the put over clip in a longer period, we monitored this only 14 days. In 4 cases, the clip was spontaneously released from the stomach wall, in the other cases, the clip was always in its initial position. Performing the autopsy, we found out no presence of the released clip in the animals' digestive system. In 11 other cases, the stomach wall was always vital after removing the clip, at the base, there was a fixed sharply demarcated scar and the surrounding mucosa was macroscopically normal. On the outside stomach wall, there was only a scar, in some cases, there was a big omentum adhering to the scar. The clip is supposed to be released from the stomach wall some time and to get out of the body per vias naturales. There is a risk of an obstacle in the small intestine or a risk of the perforation of the digestive system caused by the clip going through. We noticed no complication here. If the clip stayed in the position, ligamentous proces could develop in the surroundings of the clip and this process could eventually cause a stenosis of the organ. In this respect, there is a lack of clinical experience of using the over clip and the duration of our post-operative monitoring was insufficient to answer this question. Another risk of using the OTSC clip is a possible injury of the organ by the endoscope with the put over clip going through. The over clip is placed by a special end which is fixed at the end of the endoscope and increases its diameter. If the manipulation was inconsiderate, the wall of the hollow organ we would be just going through could be injured. In our experiment, it happened in one case while we were going through with the endoscope with the inserted over clip, a spasmus of the esophagus occurred. In our effort to get with the endoscope into the stomach, we caused a longitudinal perforation of the distal esophagus. If this were a human patient, it could have fatal consequences. In our case, there were no complications, the animal thrived well and the only consequence was a stenosis of the distal esophagus - see the results.

There are frequent disscussions about the orientation and handling of the instruments in the abdominal cavity. In our opinion, the space orientation is similar to that one in the common laparoscopy after training, the view of the endoscope is, however, considerably smaller. The manipulation space is insufficient for the instruments, there is a significant lack of triangular arrangement like in classic laparoscopy. The considerable limit is a size of the instrumetarium which has to go through a narrow channel of the endoscope and has short grip branches. Thanks to the foreign co-operation, we had an opportunity to use special prototypes of instruments having been developed specifically for the NOTES technique besides classic endoscopic instruments in our experiment. Although we had a possibility to use these NOTES instruments, which surely resulted in a better manipulation, we cannot imagine to operate safely in the abdominal cavity under these circumstances. It is well known that some pathological changes of the operated place cause intraoperative complications and worsen the practicability of the surgery. In some cases, it is necessary to convert to the open surgery because of the occurred complications. A frequent cause of the conversion is a confusion of the operated area due to adhesions or a confusion of the operating area due to hemorrhage. It is necessary to point out that the clarity and the handling area of the laparoscopy is much better than of the NOTES technique. Quite a number of authors who tried the NOTES technique recommend a combination of the NOTES technique and laparoscopy, so called hybrid NOTES technique. To hold the actual surgery we use the NOTES technique and if a higher safety and a better view of the abdominal cavity are required, we put one laparoscopic port and use classic laparoscopic optics. However, an advantage of the NOTES technique is lost in this case - the continuity of the abdominal wall is broken and a scar develops. This influences the cosmetic effect and besides, a hernia in the scar may occur. In this case, there is only little difference between the hybrid NOTES technique and the technique of single port incision laparoscopy (SILS technique) which means a variant of classic laparoscopy using only one approach into the abdominal cavity $(25,26,27)$.

The last question is a portability of all results from experimental animal studies in human medicine. In our opinion, the occurence of early infection in animals is caused by the environment where these animals can be found, that's why it cannot be taken in account during the evaluation of the NOTES technique. The animals' curative and reparation processes differ from the human ones, which we have proved many times in a lot of experimental studies in pigs performed at our department. The evidence of this claim is the healed perforation of the pig's esophagus described here.

Many funds and much human energy have been invested into the development and research of the NOTES technique but its benefits, safety and practical use in general clinical practice still remain an unanswered question. It is necessary to realize that it can be a blind way of the development and research. It is sure that other experimental works will have to be done and these will finally evaluate the benefits of the NOTES technique.

\section{Conclusion}

With regard to the performed experiment where we obtained practical experience with the pure NOTES technique and the obtained results, we can claim that the pure NOTES technique is currently not suitable to be used in general clinical practice. If there is a sufficient training and enough experience, it is possible to review the abdominal cavity optically with some restrictions but the available instrumentarium enables no safe surgery. This is already used in a limited number in some departments of the world $(6,7)$. However, it is possible that the pure NOTES technique could be used for certain kind of surgeries in the future if new instruments will be developed being more useful. In our opinion, another contribution of this work is obtaining some experience relating to using the OTSC clip we can already use in some situations in general 
clinical practice. If the OTSC clip is used by an experienced endoscopist, it is a safe way of the gastrotonomy closure, perforation of stomach, eventually perforation of colon on the prepared intestine. Strict indication criteria and conditions for the OTSC clip have to be specified to be used in general clinical practice because using the over clip has its risks and possible complications.

\section{References}

1. Whang HS, Thaler K. Natural orifice transluminal endoscopic surgery. Where are we going? World J Gastroenterol 2010; 16 (35): 4370-4373.

2. Auyang ED, Santos BF, Enter DE, Hungness ES, Soper NJ. Natural orifice translumenal endoscopic surgery (NOTES) a technical review. Surg Endosc 2011, http: //www.ncbi.nlm.nih.gov/pubmed/21553172.

3. Zonča P, Neoral Č, Malý T, Hájek M, Lerch M. Co přináší NOTES? Rozhl Chir 2007; 11 (86): 576-580.

4. Earle DB, Desilets DJ, Romanelli JR. NOTES transgastric abdominal wall hernia reapir in a porcine model. Hernia 2010; 14: 517-522.

5. Rieder E, Martinec DV, Dunst CM, Swanström LL. A novel technique for natural orifice endoscopic full-thickness colon wall resection: An experimental pilot study. J Am Coll Surg, 2011; http: //www.journalacs. org/article/S1072-7515\%2811\%2900379-6/abstrakt.

6. Onders PR, McGree FM, Marks J, Ghak A, Rosen JM, Ignagni A, Faulx A, Schomisch S, Ponsky J. Natural orifice transluminal endoscopic surgery (NOTES) as a diagnostic tool in intensive care unit. Surg Endosc 2007; 21: 681-683.

7. Onders PR, McGree FM, Marks J, Ghak A, Schilz R, Rosen JM, Ignagni A, Faulx A, Elmo MJ, Schomisch S, Ponsky J. Diaphragm pacing with natural orifice transluminal endoscopic surgery: potentical for difficult-to-wean intensive care unit patients. Surg Endosc 2007; 21: 475-479.

8. Perretta S, Dallemagne B, Coumaros D, Marescaux J. Natural orifice transluminal endoscopic surgery: Transgastric cholecystectomy in a survival porcine model. Surg Endosc 2008; 22: 1126-1130.

9. Abe N, Takeuchi H, Ueki H, Matsuoka H, Yanagida O, Masaki T, Mori T, Sugiyama M, Atomi Y. Cholecystectomy by a combined transgastric and transparietal approach using two flexible endoscopes. J Hepatobiliary Pancreat Surg 2009; 16: 25-30.

10. Chamberlain RS, Sakpal SV. A comprehensive review of singleincision laparoscopic surgery (SILS) and natural orifice transluminal endoscopic surgery (NOTES) techniques for cholecystectomy. J Gastrointest Surg 2009; 13 (9): 1733-1740.

11. Schurr MO, Hartmann C, Ho CN, Fleisch C, Kirschniak A. An over-the-scope clip (OTSC) system for closure of iatrogenic colon perforations: results of an experimental survival study in pigs. Endoscopy 2008; 40 (7): 584-588.

12. Jovanovic I, Zimmermann L, Fry LC, Mönkemüller K. Feasibility of endoscopic closure of an iatrogenic colon perforation occuring during colonoscopy. Gastrointest Endosc 2011; 73 (3): 550-555.

13. Alonso S, Dorcaratto D, Pera M, Seoane A, Dedeu JM, Pascual M, Gil JM, Courtier R, Bory F, Grande L. Incidence of iatrogenic perforation during colonoscopy and their treatment in a university hospital. Cirulat Esp 2010; 88 (1): 41-45.

14. Merchea A, Cillinance DC, Sawyer MD, Iqbal CW, Baron TH, Wigle D, Sarr MG, Zielinski MD. Esophagogastroduodenoscopy-associated gastrointestinal perforations: a single-center experience. Surgery 2010; 148 (4): 876-882.
15. Šimek K, Orlík J. Iatrogenní poranění tračníku při kolonoskopii. Rozhl Chir 2001; 80 (4).

16. Kratt T, Küper M, Traub F, Ho CN, Schurr MO, Königsrainer A, Granderath FA, Kirschniak A. Feasibility study for secure closure of natural orifice transluminal endoscopic surgery gastrotomies by using overthe-scope clips. Gastrointest Endosc 2008; 68 (5): 993-996.

17. Schurr MO, Hartmann C, Kirschniak A, Ho CN, Fleisch C, Buess G. Experimental study on a new method for colonoscopic closure of large-bowel perforation with the OTSC clip. Biomed Tech (Berl) 2008; 53 (2): 45-51.

18. Magdeburg R, Collet P, Post S, Kaehler G. Endoclipping of iatrogenic perforation to avoid surgery. Surg Endosc 2008; 22 (6): 1500-1004.

19. Junquera F, Martinez-Bauer E, Miquel M, Fort M, Gallach M, Campo EBR. OVESCO: un sistema prometedor de cierre endoscopico de las perforationes del tracto digestivo. Gastroenterol Hepatol. 2011; http: //www.elsevier.es/en/node/2510147.

20. Albert JG, Friedrich-Rust M, Woeste G, Strey C, Bechstein WO, Zeuzem S, Sarrazin C. Benefit of a clipping in use in intestinal bleeding and intestinal leake. Gastrointest Endosc 2011; http: //www.giejournal. org/article/S0016-5107\%2811\%2901350-2.

21. Repici A, Arezzo A, deCaro G, Morino M, Pagano N, Rando G, Romeo F, DelConte G, Danese S, Malesci A. Clinical experience with a new endoscopic over-the-scope clip system for use in the GI tract. Dig Liver Dis 2009; 41 (6): 406-410.

22. Sodergren MS, Pucher P, Clark J, James DCR, Sockett J, Matar $\mathbf{N}$, Teare J, Yang GZ, Darzi A. Disinfection of access orifice in NOTES: evaluation of the evidence base. Diagn Ther Endosc 2011; http: //www. ncbi.nlm.nih.gov/pmc/articles/PMC3138109/?tool=pubmed.

23. Moran EA, Gostout CJ, McConico AL, Michalek J, Huebner M, Bingener J. Assessing the invasiveness of NOTES perforated viscus repair: a comparative study of NOTES and laparoscopy. Surg Endosc 2011; Assessing the invasiveness of NOTES perforated viscus repair: a comparative study of NOTES and laparoscopy.

24. von Delius S, Schorn A, Grimm M, Schneider A, Wilhelm D, Schuster T, Stangassinger M, Feussner H, Schmid RM, Meining A. Naturalorifice transluminal endoscopic surgery: low pressure pneumoperitoneum is sufficient and is associated with an improved cardiopulmonary response (pressure pig study). Endoscopy 2011; https: //www.thieme-connect.com/ DOI/DOI? 10.1055/s-0030-1256559.

25. Sanchez-Salas RE, Barret E, Watson J, Stakhovskyi O, Cathelineau X, Rozet F, Galiano M, Rane A, Desai MM, Sotelo R, Vallancien G. Current status of natural orifice trans-endoscopic surgery (NOTES) and laparoscopic single site surgery (LESS) in urologic surgery. Int Braz J Urol 2010; 36: 385-400.

26. Schomish SJ, Furlan JP, Andrews JM, Trunzo JA, Ponsky JL, Marks JM. Comparison of anterior transgastric acces techniques for natural orifice translumenal endoscopic surgery. Surg Endosc 2011; http: // www.springerlink.com/content/v581220754408p73/.

27. Wen L, Hong X, Zi-Kai W, Zhi-Ning F, Shan-Duo B, Duo-Wu Z, Xu R, Bing H, Yong-Hui H, Ming-Jun S, Jie L, Wen L, Ping X, Si-De L, Jian-Guo X. Natural orifice translumenal endoscopic surgery (NOTES): Patient's perceptions and attitides. Dig Dis Sci, 2011; http: //www.springerlink.com/content/j341456728813774/.

Received December 16, 2011. Accepted December 20, 2011. 